\title{
Analisis Waktu Tunggu Pelayanan Poliklinik Paru di Rumah Sakit Umum Daerah (RSUD) Tangerang
}

\section{Analysis of Waiting Time Lung Polyclinic Service at The Regional General Hospital (RSUD) Tangerang}

\author{
Erlina Puspitaloka Mahadewi ${ }^{*}$, Ade Heryana ${ }^{1}$, Yatmi Kurniawati ${ }^{1}$, Iyan Ayuba ${ }^{2}$ \\ ${ }^{1}$ Program Studi Kesehatan Masyarakat, Universitas Esa Unggul \\ *email : erlina.puspitaloka@esaunggul.ac.id \\ ${ }^{2}$ Program Studi Manajemen, Fakultas Ekonomi, Universitas Gorontalo
}

\begin{abstract}
Service queue is a clasically service problem at hospital. The conotation of patient queue both positive and negative. When the patients more prefer to our services, it's a positive matter. But when patients forced to waiting the service because the length of service time, it's a negative matter. It's suggested that the increasing of inpatients service affected to outpatients, because doctors who served often late to outpatient services room. This condition led to patient's unsatisfaction due to unappropriateness of service time standards. This study aimed to analyze the determinants of length of outpatient services waiting time who served by pulmonologist at general hospital Tangerang City. Qualitative design was held to get deepest information about length of pulmologist service time. Five informants were recruited i.e outpatient service coordinator, nurse, pulmonologist, and two patients who complained to length of waiting time. Result there were conditions that affected the length of service time i.e lack of nurse skill particularly in spirometre operation, inadequately amount of chair at waiting room and trobleshooting of information system, unavailable of service procedure that led to imprecise of newly patient service, working condition wasn't support to pulomonogist service i.e inpatient service activity. It's suggested to complete with procedure operation standard and enhance infrastructure budget to update the information system and the addition of chairs at waiting room.
\end{abstract}

Keywords; outpatient service, pulmonary clinic, service time, waiting time

\begin{abstract}
Abstrak
Peningkatan jumlah pasien rawat inap diduga mempengaruhi waktu tunggu pelayanan rawat jalan akibat petugas terlambat datang ke poliklinik. Hal ini berdampak pada ketidakpuasan pasien karena ketidaksesuaian dari standar yang telah ditetapkan. Atas dasar itulah maka menarik untuk diadakan penelitian tentang faktor penyebab lamanya waktu tunggu pelayanan rawat jalan. Penelitian ini bertujuan untuk mengetahui penyebab lamanya waktu tunggu pasien di Pelayanan Rawat Jalan Poliklinik Penyakit Paru RSUD Kota Tangerang. Penelitian ini menggunakan pendekatan kualitatif dengan tujuan mendapatkan informasi yang lebih aktual dan akurat mengenai faktor penyebab lamanya waktu tunggu di Pelayanan Rawat Jalan Poliklinik Paru RSUD Kota Tangerang. Informan terdiri dari informan kunci, informan utama dan informan pendukung. Gambaran penyebab lamanya waktu tunggu pelayananan di bagian Instalasi Rawat Jalan dalam pelayanan di Poliklinik Paru RSUD Kota Tangerang, yaitu: perawat masih memerlukan pelatihan dan pengembangan dalam mengoperasikan alat spirometri, fasilitas ruang tunggu yaitu kursi yang masih belum mencukupi dan program SIMRS (system infromasi manajemen Rumah
\end{abstract}


Sakit) yang harus lebih baik lagi untuk menunjang kegiatan di pelayanan poliklinik paru, prosedur pemberian pelayanan masih belum lengkap, SOP (Standar Operasional Prosedur) alur pelayanan belum ditetapkan, sehingga pada pasien baru sering terjadi salah prosedur, tingginya jumlah tindakan pasien paru rawat inap menyebabkan lamanya pelayanan. Saran sebaiknya manajemen rumah sakit melengkapi SOP pada instalasi rawat jalan, penambahan anggaran terkait pembaharuan SIMRS dan penambahan fasilitas tempat duduk pasien.

Kata kunci; waktu pelayanan, waktu tunggu, klinik rawat jalan, poliklinik paru

\section{PENDAHULUAN}

Standar Pelayanan Minimal Rumah Sakit sebagai amanah yang tertuang dalam Kepmenkes Nomor 129/Menkes/SK/II/2008 tentang hal ini telah menjadi keharusan di setiap layanan kesehatan yang ada, untuk menjamin kualitas layanan prima sebagai hasil akhir dari produk kesehatan yang ditawarkan. Setiap unit pelayanan dan manajemen rumah sakit telah menentukan Standar Pelayanan Minimal (SPM) sebagai acuan standar pelayanan yang harus dipenuhi. Salah satu indikator SPM rawat jalan yang berhubungan dengan antrian adalah lama waktu tunggu adalah 60 menit. Antrian yang lama merupakan salah satu permasalahan yang banyak ditemukan di instalasi rawat jalan rumah sakit (Wijono, 2009).

Permasalahan antrian pelayanan (service queue) merupakan hal klasik dalam insdustri jasa kesehatan. Saat melihat antrian pasien di rumah sakit, seseorang dapat berasosiasi dengan hal positif (karena pasien menyukai pelayanan) atau berkonotasi negatif (karena lamanya pelayanan dan pasien terpaksa harus menunggu). Sejak diterapkan pelayanan BPJS kesehatan tahun 2014, kata "antri" merupakan diskursus yang selalu didiskusikan baik dalam kajian ilmiah maupun keluhan pasien (Heryana \& Puspitaloka, 2018).

Rumah Sakit Umum Daerah Kota Tangerang, mempunyai standar waktu dalam pelayanan rawat jalan yaitu kurang dari atau sama dengan 60 menit. Berdasarkan data indikator mutu instalasi rawat jalan yaitu pada indikator waktu tunggu pelayanan poliklinik paru adalah pada tahun 2016 waktu tunggu lebih dari 60 menit 85\%. Lalu pada tahun 2017 lama waktu tunggu lebih dari 60 menit meningkat jadi 92,94\%. Bahkan pada tahun 2018 (Januari - April) seluruh pasien mengalami waktu tunggu lebih dari 60 menit.

Berdasarkan data absensi petugas sudah sesuai dengan aturan kedisiplinan yang telah ditetapkan oleh Direktur RSUD Kota Tangerang. Dugaan sementara penyebab dari lamanya waktu tunggu pelayanan poliklinik paru karena jumlah pasien rawat inap yang banyak, sehingga petugas terlambat datang ke poliklinik dan berdampak pada ketidakpuasan pasien karena ketidaksesuaian dari standar yang telah ditetapkan.

Hasil wawancara awal secara langsung awal bulan Februari 2018 di poliklinik paru RSUD Kota Tangerang pada 5 orang pasien menunjukkan waktu tunggu pasien diatas 60 menit untuk mendapatkan pelayanan medis, yaitu mulai dari kedatangan pasien untuk dilakukan pemeriksaan tanda-tanda vital sampai mendapatkan pemeriksaan oleh dokter. Tidak jarang pasien langsung menyampaikan keluhannya karena menunggu terlalu lama untuk mendapatkan pemeriksaan oleh dokter, dimana waktu bertemu untuk diperiksa dokter dirasakan terlalu singkat jika dibandingkan dengan waktu yang dihabiskan untuk menunggu panggilan diperiksa oleh dokter.

Penelitian yang dilakukan Laeliyah dan Subekti (2017) di RSUD kabupaten Indramayu menunjukkan hal yang sama, yaitu rerata waktu tunggu pelayanan pasien rawat jalan selama 70,18 menit dan sebagian besar kategori waktu lama (> 60 menit). Hasil penelitian juga menunjukkan lamanya waktu tunggu 
berhubungan dengan kepuasan pasien.Faktor penyebab penurunan kualitas pada suatu sistem pelayanan dapat ditelusuri dengan quality control tools, salah satunya adalah fishbone chart atau diagram Ishikawa. Diagram ini dikembangkan tahun 1960 oleh Dr. Kaoru Ishikawa yang berbentuk tulang ikan.

Diagram fishbone merupakan suatu alat visual untuk mengidentifikasi, mengeksplorasi dan secara grafik menggambarkan secara detail semua penyebab yang berhubungan dengan suatu permasalahan. Menurut Scarvada (2004), konsep dasar dari diagram tulang ikan adalah permasalahan mendasar diletakkan pada bagian kanan dari diagram atau pada bagian kepala dari kerangka tulang ikannya. Penyebab permasalahan digambarkan pada sirip dan durinya. Kategori penyebab permasalahan yang sering digunakan sebagai langkah awal meliputi man power (orang), measurement (pengukuran), machine (mesin), materials (bahan baku), methods (metode), dan mother nature (lingkungan). Keenam penyebab munculnya masalah ini sering disingkat 6M. Penyebab lain dari masalah selain $6 \mathrm{M}$ tersebut dapat dipilih jika diperlukan. Untuk mencari penyebab dari permasalahan, baik yang berasal dari $6 \mathrm{M}$ seperti dijelaskan di atas maupun penyebab yang mungkin lainnya dapat digunakan teknik brainstorming.

Diagram fishbone umumnya digunakan pada tahap mengidentifikasi permasalahan dan menentukan penyebab dari munculnya permasalahan tersebut. Selain digunakan untuk mengidentifikasi masalah dan menentukan penyebabnya, diagram fishbone juga dapat digunakan pada proses perubahan. Scarvada (2004) menyatakan diagram fishbone ini dapat diperluas menjadi diagram sebab dan akibat (cause and effect diagram). Perluasan (extension) terhadap diagram fishbone dapat dilakukan dengan teknik menanyakan "mengapa ?" sampai lima kali atau disebut five why (Gambar 1).

Penelitian ini bertujuan untuk mendapatkan informasi secara mendalam mengenai proses pelayanan pasien di poliklinik paru dan diharapkan dapat ditarik benang merah penyebab lamanya waktu tunggu pelayanan. Informasi dikumpulkan pada aspek-aspek sebagai berikut: sumberdaya manusia, sarana prasarana, prosedur dan lingkungan kerja.

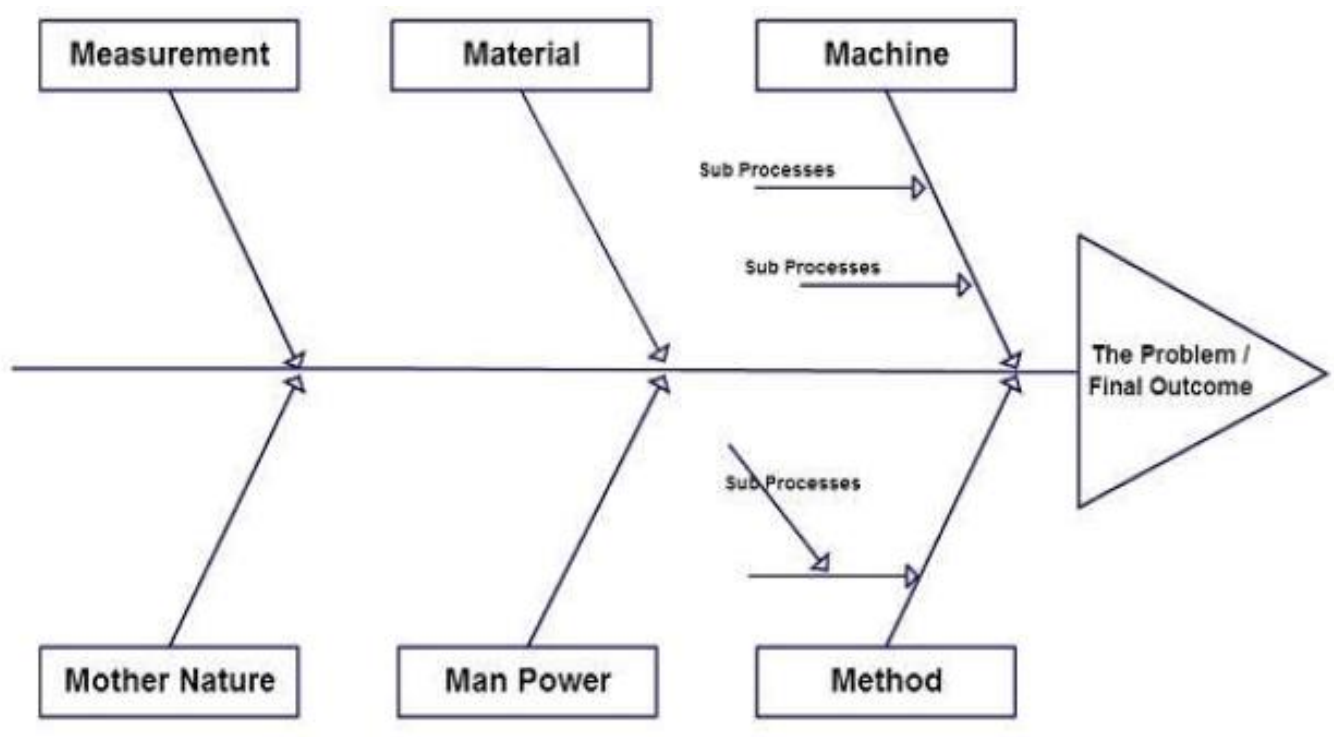

Gambar 1. Bagan diagram tulang ikan (fishbone chart) sebagai kerangka teori (Sumber: Ishikawa dalam Scarvada, 2004) 


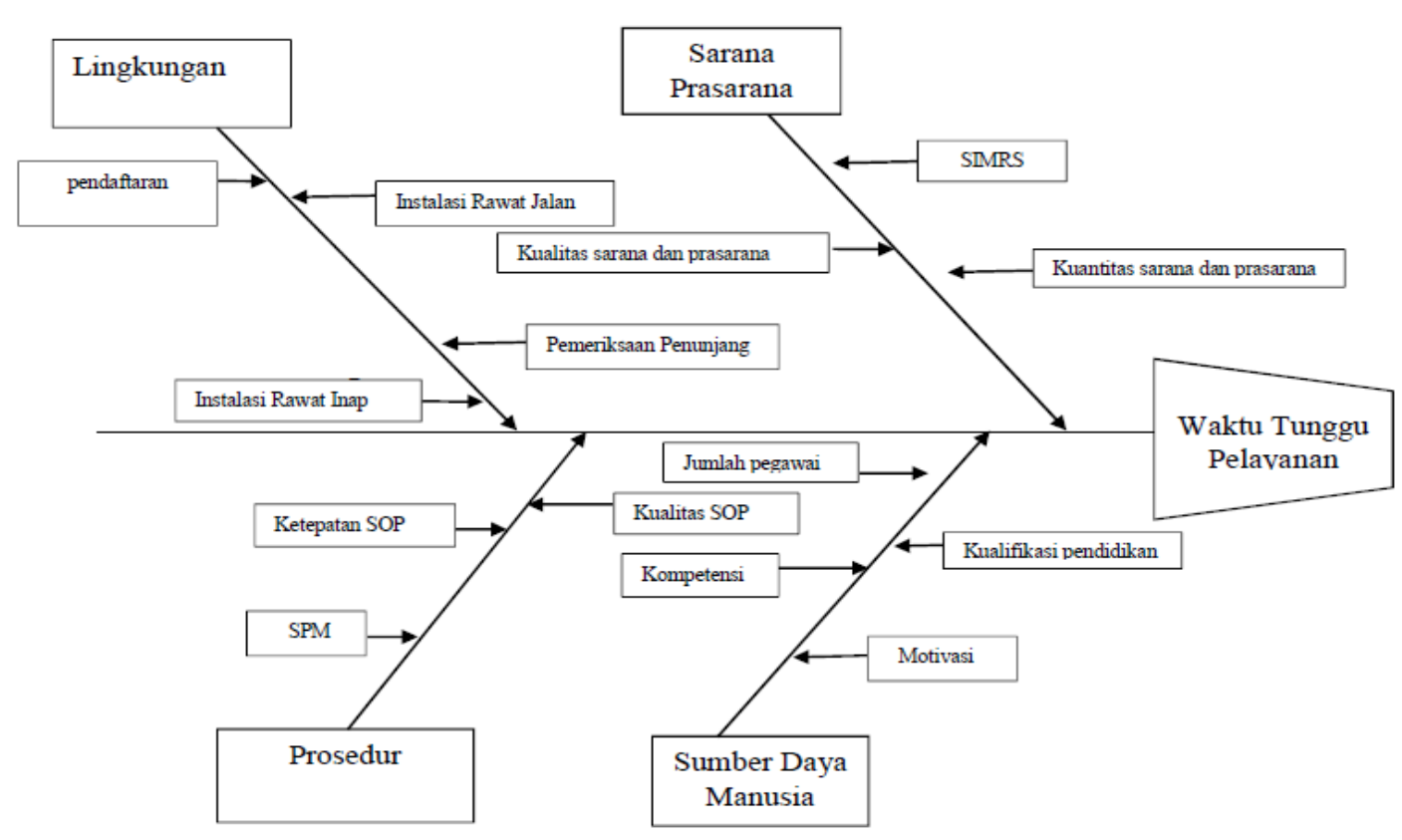

Gambar 2. Kerangka konsep penelitian

\section{METODE}

Dalam penelitian ini indikator $6 \mathrm{M}$ yang dipilih adalah manpower (SDM), methods (prosedur), machine (sarana prasarana) dan mother nature (lingkungan kerja). Setiap indikator terdiri dari dimensi-dimensi yang dipilih berdasarkan brainstorming dengan manajemen rumah sakit (Gambar 2). Sumber daya manusia merupakan petugas yang melakukan pelayanan rawat jalan meliputi perawat dan dokter spesialis. Sarana prasaranan merupakan alat serta penunjang dalam melaksanakan kegiatan pelayanan rawat jalan. Prosedur merupakan dokumen yang berisi serangkaian instruksi tertulis yang dibakukan mengenai berbagai proses penyelenggaraan administrasi perkantoran yang berisi cara melakukan pekerjaan, waktu pelaksanaan, tempat penyelenggaraan dan petugas yang berperan dalam proses pelayanan rawat jalan. Lingkungan kerja merupakan kondisi kerja yang mendukung kegiatan pelayanan rawat jalan.

Penelitian dilakukan di poliklinik paru RSUD kota Tangerang pada bulan Mei-Juli 2018 dengan menggunakan desain kualitatif (Saryono, 2013). Seluruh indikator diukur dengan pedoman wawancara kepada informan terpilih. Sebagai informan kunci adalah koordinator layanan rawat jalan. Informan utamanya adalah perawat dan dokter spesialis paru. Sedangkan informan pendukung adalah pasien yang mengeluhkan lamanya pelayanan. Validitas data diukur dengan teknik triangulasi sumber dan triangulasi metode.

Variabel yang diteliti antara lain: 1) Lingkungan (pendaftaran, instalasi rawat jalan, instalasi rawat inap, pemeriksaan penunjang); 2) Sarana prasarana (SIRS, kualitas, kuantitas); 3) Prosedur (SPM, ketepatan, kualitas); dan 4) Sumber daya manusia (motivasi, kompetensi, kualifikasi pendidikan, jumlah pegawai).

\section{HASIL DAN PEMBAHASAN Sumber Daya Manusia}

Berdasarkan hasil wawancara diketahui bahwa petugas dalam memberikan pelayanan sudah sesuai dengan kompetensi karena petugas sudah ikut pelatihan-pelatihan yang menunjang dalam pemberian pelayanan di Poliklinik Paru serta berprilaku ramah dan sopan, namun masih ada satu alat yaitu 
spirometri yang petugasnya belum dilatih untuk mengoperasikan alat tersebut hanya training dari vendor saja. Berikut skrip wawancara yang dilakukan kepada Ka. Ru Instalasi Rawat Jalan, perawat paru, spesialis paru dan pasien paru rawat jalan:

"sudah sesuai mas ON juga sudah ikut pelatihan Bronchoscopy, TB DOTS cuma pada tindakan spirometri belum ada yang dilatih, jadi petugas yang melakukan belajar sendiri saja tetapi belum faham dengan hasilnya, saya sudah mengajukan ke bagian litbang untuk pelatihan spirometri tapi belum di acc, mas ON hanya ikut training saja lewat vendor." (informan kunci)

"untuk kompetensi saya sudah ikut pelatihan BTCLS, Bronchoscopy, TB DOTS, untuk spesialis sudah terstandar kompetensi."(informan utama 1)

"Oman sudah bagus, sudah pelatihan Bronchoscopy dan TB DOTS, ngetiknya juga cepet, ramah sama pasien, kalo ON tidak masuk..pernah sakit jadi dikerjain sendiri jadi lama." (informan utama 2)

"ramah sopan." (informan pendukung 1)

Unsur manajemen dalam pemenuhan SDM sangat dibutuhkan hal ini sesuai dengan Handoko (2009) "Man" merujuk pada sumber daya manusia yang dimiliki oleh organisasi dalam manajemen, faktor manusia adalah yang paling menentukan. Manusia yang membuat tujuan dan manusia pula yang melakukan proses untuk mencapai suatu tujuan. Tanpa ada manusia tidak adanya suatu proses kerja, sebab pada dasarnya manusia adalah makhluk pekerja. Oleh karena itu, manajemen timbul karena adanya orang-orang yang bekerjasama untuk mencapai tujuan.

Untuk mencapai tujuan agar pelayanan di poliklinik paru tidak lama, disarankan kepada manajemen rumah sakit agar memberikan pelatihan penggunaan alat spirometri secara komprehensif. Dengan keterampilan SDM yang meningkat diharapkan proses diagnostik paru menjadi lebih cepat.

\section{Sarana dan Prasarana}

Dari hasil wawancara mendalam, SIMRS dalam jaringan tidak ada kendala sehingga proses pendaftaran bisa berjalan dengan cepat. Akan tetapi alangkah baiknya jika hasil foto rontgen bisa terhubung ke komputer poliklinik paru sehingga dapat mempercepat proses pelayanan. Dengan penerapan teknologi ini, spesialis tidak perlu menggambar atau jika ada pasien yang lupa membawa hasil rontgen tidak ada masalah. Berikut skrip wawancara mendalam terkait SIMRS dengan informan kunci, informan utama:

"SIMRS saat ini tidak ada masalah, jaringan oke." (informan kunci)

"SIMRS untuk jaringan sudah oke tapi dalam programnya belum bisa nyambung dari hasil rontgen ke pc poliklinik paru dan program SIMRS belum bisa membuat gambar di PC sehingga dokter masih membuat catatan sendiri pada register poliklinik paru." (informan utama 1)

"kalo bisa hasil fhoto langsung track ke pc poliklinik paru" (informan utama 2)

"cepet pas daftarnya" (informan pendukung 1)

"cepet siy dipendaftaran." (informan pendukung 2)

"asistennya ramah" (informan pendukung 2)

Dalam Permenkes No 82 tahun 2013 tentang Sistem Informasi Manajemen Rumah Sakit (SIMRS) disebutkan bahwa sistem teknologi informasi komunikasi memproses dan mengintegrasikan seluruh alur proses pelayanan Rumah Sakit dalam bentuk jaringan koordinasi, pelaporan dan prosedur administrasi untuk 
memperoleh informasi secara tepat dan akurat, dan merupakan bagian dari Sistem Informasi Kesehatan. Suatu alat yang berhubungan dengan alat penampung, penyimpanan dan untuk melakukan proses produksi serta menyangkut macam teknologi yang berkaitan dengannya (Asmuni, 2009). Dengan demikian SIMRS yang menghubungkan poliklinik paru dengan pelayanan radiologi diharapkan dapat mempercepat proses pelayanan oleh dokter spesialis.

Dari hasil wawancara mendalam terkait sarana prasarana juga diperoleh hasil bahwa masih kurang terkait ruang tunggu dan gedung. Kondisi poliklinik dengan pasien yang banyak idealnya mengoperasikan 2 spesialis setiap harinya (Nasution, 2014). Berikut skrip hasil wawancara terkait sarana dan prasarana yang ada di Poliklinik Paru RSUD Kota Tangerang:

"kalo menurut saya sarana dan prasarana sudah sesuai, hanya saja letak poliklinik paru yang masih belum terstandar karena masih ada orang yang lalu lalang." (informan kunci)

"kuantitas sarana dan prasarana sudah sesuai." (informan utama 1)

"saya fikir tadinya Poliklinik paru buka 2, karena pasien yang banyak." (informan utama 2)

"tidak ada pengeras suara di poliklinik paru" (informan pendukung 1)

"ruang tunggu di poli bedah sempit lebih lega disini" (informan pendukung 2)

\section{Prosedur}

Dari hasil wawancara masih terdapat SOP yang belum ada dan harus dipenuhi. SOP yang belum ada adalah penggunaan masker dan alur pasien. SOP yang ada pelaksanaannya masih belum konsisten sehingga banyak kendala yang ditemukan (Palutturi, 2015). Kondisi ini menyebabkan kesalahan prosedur dalam pelayanan. Berikut hasil wawancara terkait standar operasional prosedur terkait pelayanan poliklinik paru :

"kalo menurut saya masih banyak yang kurang, misalnya SOP penggunaan masker, SOP alur pasien poliklinik paru" (informan kunci)

"alur pasien poliklinik paru berbeda dengan pasien poliklinik yang lainnya, dan memang belum ada SOP alur pasien poliklinik paru." (informan utama 1)

"Masih banyak yang kurang" (informan utama 2)

"saya diberikan informasi dengan petugas adminnya." (informan pendukung 1)

"petugas memberikan informasi.tapi kurang jelas jadi saya salah simpen barkot kirain sama dengan yang poli lainnya." (informan pendukung 2)

Pada hasil telaah dokumen ditemukan 12 (dua belas) dokumen SOP yang ada di Poliklinik Paru dan masih ada SOP yang belum ditetapkan. Dari hasil wawancara pelaksanaan SOP yang sudah ditetapkan masih ada yang belum sesuai dalam pelaksanaannya. Pada hasil telaah dokumen dan observasi SOP yang belum ada yaitu alur pelayanan Poliklinik Paru. Berikut hasil wawancara mendalam terkait pelaksanaan dari SOP tersebut:

"pelaksanaan SOP masih simpang siur, masih ada yang tidak sesuai dengan SPO ." (informan kunci)

"pelaksanaan SOP masih belum sesuai." (informan utama 1)

"sepertinya SOP banyak yang tidak dijalankan atau belum sesuai". (informan utama 2) 
"petugasnya sudah memberikan informasi, ramah, tapi banyaknya yang jelasin asistennya dokternya gak ngomong gimana-gimananya." (informan pendukung 1)

"petugasnya siy kasih tahu tapi..ga jelas saya fikir penyakit dalam sama paru sama” (informen pendukung 2).

Metode adalah suatu tata cara yang memperlancar jalannya pekerjaan manajer. Sebuah metode dinyatakan sebagai penetapan cara pelaksanaan kerja suatu tugas dengan memberikan berbagai pertimbangan-pertimbangan kepada sasaran, fasilitas-fasilitas yang tersedia dan penggunaan waktu, serta uang dan kegiatan usaha (Dhamanti, 2013). Perlu diingat meskipun metode baik sedangkan orang yang melaksanakan tidak mengerti atau tidak memiliki pengalaman maka hasil tidak akan memuaskan, manajemen untuk mengelola sejumlah unsur dibutuhkan suatu metode yang baku berupa Standard Operational Procedure (Handoko, 2009). Dengan demikian SOP dapat mempermudah petugas dan memberi arahan bagi petugas dalam menjalankan tugas (Basri, 2015). SOP juga menjamin keselamatan petugas serta keselamatan pasien (patient safety).

\section{Lingkungan}

Dari hasil wawancara terkait pemeriksaan penunjang untuk radiologi banyak antrian sehingga hasil menjadi lama karena hasil belum bisa link ke PC poliklinik paru. Informasi ini mirip dengan wawancara tentang sarana prasarana. Pada pemeriksaan penunjang masih terdapat kendala karena hasil ekspertise yang lama, berikut hasil wawancara terkait pemeriksaan penunjang:

"hasil rontgen agak lama dalam ekspertise (hasil)" (informan kunci)

"pada radiologi untuk foto tidak nyambung ke SIMRS, hasil ekspertise lama pada pasien kontrol hasil rontgen masih ada di instalasi radiologi, pada pasien kontrol wajib membawa hasil rontgen sebelumnya". (informan utama 1)

"hasil fhoto yang belum track ke SIMRS, jadi masih butuh fisiknya untuk menggambar." (informan utama 2)

1)

"Saya belum pernah rontgen atau ambil darah disini" (informan pendukung

"waktu itu lama pada saat saya cek lab karena banyak orang yang pada tes narkoba, terus ada ibu-ibu yang ngarahin orang-orang tes narkoba dibedain tempatnya, jadi cepet setelah itu." (informan pendukung 2)

Kondisi di Instalasi Rawat Inap untuk pasien paru banyak tindakan yang harus dilakukan segera untuk menyelamatkan atau menyembuhkan pasien tersebut. Dari hasil wawancara Instalasi Rawat Inap menjadi salah satu penyebab lamanya waktu tunggu pelayanan di Instalasi Rawat Jalan Poliklinik Paru RSUD Kota Tangerang. Berikut hasil wawancara terkait instalasi rawat inap:

"pada pasien kontrol dari rawat inap terkadang masih belum diberikan penjelasan atau pasien sendiri yang lupa, pasien dirawat inap terkadang ada tindakan cyto seperti WSD, Funksi pleura yang teradang bersamaan dengan jam jadwal spesialis tersebut dipoliklinik." (informan kunci)

"untuk instalasi rawat inap banyak tindakan yang harus segera dilakukan seperti WSD, Fleura ini sering terjadi pada saat waktunya jam jaga poliklinik, untuk tindakan bronchoscopy terjadwal, biasanya diluar jam jaga poliklinik" (informan utama 1) 
"di rawat inap pada saat visite terkadang masih menunggu mereka tukeran shift, saya kalo turun naik..capek juga." (informan utama 2)

"belum pernah dirawat disini jadi belum tahu". (informan pendukung 1)

"saya tidak pernah dirawat disini, tapi ada saudara dirawat disini saya jagain..dokternya periksanya pagi-pagi”. (informan pendukung 2)

Pelayanan kesehatan yang bermutu adalah pelayanan kesehatan yang dapat memuaskan setiap pemakai jasa pelayanan kesehatan yang sesuai dengan tingkat kepuasan rata-rata serta penyelengaraannya sesuai dengan standar dan kode etik profesi (Parasuraman et al., 2010). Sama halnya dengan berbagai pelayanan kesehatan lainnya, maka salah satu syarat pelayanan rawat jalan yang baik adalah pelayanan yang bermutu (Danakusuma, 2012). Karena itulah untuk dapat menjamin mutu pelayanan rawat jalan tersebut, maka program menjaga mutu pelayanan rawat jalan perlu pula dilakukan (Muninjaya, 2016).

Untuk ini perlu diperhatikan bahwa sekalipun prinsip pokok program menjaga mutu pada pelayanan rawat jalan tidak banyak berbeda dengan berbagai pelayanan kesehatan lainnya (Wolper, 2007). Namun, karena pada pelayanan rawat jalan ditemukan beberapa ciri khusus, menyebabkan penyelengaraan program menjaga mutu pada pelayanan rawat jalan tidaklah semudah yang diperkirakan. Ciri-ciri khusus yang dimaksud adalah(Azwar, 2010); a. Sarana, prasarana serta jenis pelayanan rawat jalan (input, process dan environment) sangat beraneka ragam, sehingga sulit merumuskan tolak ukur yang bersifat baku. b. Tenaga pelaksana yang bekerja pada sarana pelayanan rawat jalan umumnya terbatas, sehingga disatu pihak tidak dapat dibentuk suatu perangkat khusus yang diserahkan tanggung jawab menyelengarakan program menjaga mutu dari dipihak lain. Apabila beban kerja terlalu besar, tidak memiliki cukup waktu untuk menyelengarakan program menjaga mutu tersebut. c. Hasil pelayanan rawat jalan (performance) sering tidak diketahui. Ini disebabkan karena banyak dari pasien tidak datang lagi ke klinik. d. Beberapa jenis penyakit yang datang ke sarana pelayanan rawat jalan adalah penyakit yang dapat sembuh sendiri (self limiting deseases) sehingga penilaian yang objektif sulit dilakukan. e. Beberapa jenis penyakit yang datang ke sarana pelayanan rawat jalan adalah penyakit yang telah berat dan bersifat kronis, sehingga menyulitkan pekerjaan penilaian. f. Beberapa jenis penyakit yang datang berobat ke sarana pelayanan rawat jalan mungkin jenis penyakit yang penanggulangannya sebenarnya berada di luar kemampuan yang dimiliki. Keadaan yang seperti ini juga akan menyulitkan pekerjaan penilaian. g. Rekam medis yang dipergunakan pada pelayanan rawat jalan tidak selengkap rawat inap, sehingga data yang diperlukan untuk penilaian tidak lengkap. h. Perilaku pasien yang datang ke sarana pelayanan rawat jalan sukar dikontrol, dan karenanya sembuh atau tidaknya penyakit yang dialami tidak sepenuhnya tergantung dari mutu pelayanan yang diselengarakan.

Kondisi-kondisi pelayanan rawat jalan seperti yang dijelaskan oleh Azwar (2010) di atas sedikit banyak terjadi juga di poliklinik paru RSUD Kota Tangerang. Salah satunya adalah keterbatasan (baik secara kuantitas maupun kualitas pada SDM). Keterbatasan inilah yang dapat menyebabkan lamanya waktu pelayanan.

Disamping itu pelayanan poliklinik paru tidak terlepas dengan pelayanan medis dan penunjang lainnya sehingga ada faktor yang sulit dikendalikan. Misalnya banyaknya tindakan yang dilakukan pada pasien paru rawat inap dan ditambah dengan terbatasnya SDM, sudah pasti akan mempengaruhi lamanya pelayanan (Krowinski \& Steiber, 2006).

Kesalahan prosedur pelayanan yang memperlambat pelayanan tidak selamanya disebabkan oleh kesalahan manusia, namun dapat pula disebabkan 
tidak jelasnya ketentuan operasional yang ada atau bahkan disebabkan tidak adanya standar prosedur yang jelas. Kondisi bukan hanya menyebabkan rasa frustrasi pada petugas namun juga menyebabkan ketidakpuasan pasien terhadap pelayanan di poliklinik (Wijono, 2009). Terakhir yang perlu diperhatikan adalah penggunaan teknologi yang membantu proses pelayanan. Seperti penggunaan aplikasi yang dapat menghubungkan hasil foto rontgen di fasilitas penunjang dengan komputer di dokter spesialis. Ternyata bukan hanya dapat mempercepat kerja petugas, teknologi ini menghindari kemungkinan pasien ditolak periksa karena tidak membawa hasil pemeriksaan.

\section{PENUTUP}

Kondisi SDM masih terdapat petugas yang kurang terampil dalam mengoperasikan alat spirometri. Dokter spesialis harus melayani pasien paru rawat inap pada pagi hari sehingga memperlambat pelayanan di rawat jalan, sarana sistem informasi yang belum terhubung antara hasil rontgen di radiologi dengan komputer di meja dokter spesialis memperlambat proses pelayanan pemeriksaan, belum adanya prosedur alur pelayanan yang jelas menyebabkan terjadinya kesalahan prosedur administrasi yang dapat mengakibatkan proses pemeriksaan pasien menjadi lama, tingginya jumlah tindakan di instalasi rawat inap pada pasien paru juga memperlambat proses pelayanan poliklinik paru. Namun demikian kondisi ini adalah yang tidak dapat dikontrol oleh manajemen. Disarankan agar memberikan pelatihan operasionalisasi alat spirometri kepada perawat secara komprehensif, menerapkan teknologi yang dapat mempercepat pembacaan hasil rontgen oleh dokter spesialis paru, membuat SOP alur pelayanan pasien di poliklinik paru.

\section{DAFTAR PUSTAKA}

Asmuni. 2009. Pengaruh Karakteristik dan Kompetensi Perekam Medis Terhadap Waktu Tunggu Pasien Pada Pelayanan Rekam Medis Rawat Jalan di Rumah Sakit Umum DR. Pirngadi Medan Tahun 2008. [Tesis]. Pascasarjana Universitas Sumatera Utara Medan.

Azwar A. 2010. Pengantar Administrasi Kesehatan. Binarupa Aksara. Tangerang.

Basri H. 2015. Waktu Tunggu dan Cara Pembayaran di Instalasi Rawat Jalan Rumah Sakit Aloei Saboe Gorontalo. Working Paper Series No. 1. Program Magister Kebijakan dan Manajemen Pelayanan Kesehatan UGM. Yogyakarta.

Danakusuma. 2012. Perkembangan Kesehatan Masyarakat dan Kedokteran Komunitas. Bulletin FK-UI. Jakarta.

Dhamanti. 2013. Analisis Faktor yang Mempengaruhi Waktu Tunggu Pelayanan di Rekam Medis Rawat Jalan (Studi di Rekam Medis Rawat Jalan RSU Haji Surabaya). [Penelitian Ilmiah]. Universitas Airlangga Surabaya.

Handoko TH. 2009. Manajemen Edisi II. BPFE. Yogyakarta.

Heryana A \& Puspitaloka E. 2018. Kajian Antrian Pendaftaran Pasien BPJS Di RSU Kabupaten Tangerang. Universitas Esa Unggul. Jakarta.

Kemenkes RI. 2008. Kepmenkes No 129/ Menkes/ SK/ II/2008 Tentang Standar Pelayanan Minimal Rumah Sakit. Jakarta : Departemen Kesehatan Republik Indonesia.

Kepmenkes RI. 2013. Permenkes RI No 82 Tahun 2013 tentang Sistem Informasi Manajemen Rumah Sakit. Jakarta : Departemen Kesehatan Republik Indonesia.

Krowinski WJ \& Steiber RS. 2006. Measuring and Managing Patient Satisfaction. American Hospital Publishing Inc. 
Laeliyah N \& Subekti H. 2017. Waktu Tunggu Pelayanan Rawat Jalan dengan Kepuasan Pasien terhadap Pelayanan di Rawat Jalan RSUD Kabupaten Indramayu. Jurnal Kesehatan Vokasional. 1(2); 102 - 112.

Muninjaya G. 2016. Manajemen Mutu Pelayanan Kesehatan edisi 2. EGC. Jakarta.

Nasution MN. 2014. Manajemen Jasa Terpadu: Total Service Management. PT. Ghalia Indonesia. Bogor.

Palutturi S. 2015. Ekonomi Kesehatan. Penerbit: Bagian Administrasi dan Kebijakan Kesehatan FKM UNHAS. Makassar.

Parasuraman, Zeithmal, Bitner. 2010. Konsep dan Teknik Pengukuran Kualitas Produk Jasa. Kajian Bisnis dan Manajemen. 4(1); 55 - 56.

Saryono MDA. 2013. Metodologi Penelitian Kualitatif dan Kuantitatif dalam Bidang Kesehatan. Nuha Medika. Yogyakarta.

Scarvada AJ, Bouzdine-Chameeva T, Goldstein SM, Hays JM, Hill AV. 2004. Teknik Ilsutrasi Fishbone Diagrams. http://www.bppk.depkeu.go.id/pubikasi/artikel/418-artikelsoftcompetency/10999 teknik-ilustrasi-masalah-fishbone-diagrams. [diakses 01 Mei 2018].

Wijono. 2009. Manajemen Mutu Layanan Kesehatan. Airlangga Universitas Press. Surabaya.

Wolper. 2007. Admistrasi Layanan Kesehatan. EGC. Jakarta. 